Southern Illinois University Carbondale

OpenSIUC

10-2019

\title{
Adolescents' Perception of the Threat of Sexual Harassment: The Development of an Index
}

Hussein Soliman

SIUC, soliman@siu.edu

Jennifer Koran

Southern Illinois University Carbondale, jkoran@siu.edu

Amal Abdelmonem,

Qatar University

Follow this and additional works at: https://opensiuc.lib.siu.edu/cqmse_pubs

\section{Recommended Citation}

Soliman, Hussein, Koran, Jennifer and Abdelmonem, Amal. "Adolescents' Perception of the Threat of Sexual Harassment: The Development of an Index." Journal of Child Sexual Abuse (Oct 2019). doi:10.1080/10538712.2019.1667469.

This Article is brought to you for free and open access by the Counseling, Quantitative Methods, and Special Education at OpenSIUC. It has been accepted for inclusion in Publications by an authorized administrator of OpenSIUC. For more information, please contact opensiuc@lib.siu.edu. 


\section{Adolescents' Perception of the Threat of Sexual Harassment:}

The Development of an Index

Sexual harassment $(\mathrm{SH})$ of females has been a serious problem in many countries around the world (Wasti, Bergman, Glomb, \& Drasgow, 2000). Similarly, research on adolescents' exposure to the threat of sexual harassment identifies some major issues that influence the dynamics of sexual harassment, such as vulnerability and risk (Gilson, 2016), nature and types of sexual harassment (Hill \& Kearl, 2011), the difficulty of measuring adolescents' reactions (Appollis, Lund, De Varies, \& Mathews, 2015), and its effect (Lindberg, Grabe, \& Hyde 2007). Concerns over women and adolescents' experience with sexual harassment in Arab societies have been on the rise (Al-Motalak, 2017; Al-Taiar, 2015; Fahd, 2015; and Gad-Allah, 2016).

In Arab societies, especially in Egypt, young girls are exposed on a daily basis to various forms of harassment as they walk to and from schools, ride public transportation, or visit with friends (McClinton, Lund, De Vries, \& Mathews, 2015). Davidson, Butchko, Robbins, Sherd, and Gervais (2016) cited the Stop Street Harassment organization's definition of street harassment as "unwanted whistling, leering, sexist, homophobic or transphobic slurs, persistent requests for someone's name, number or destination after they've said no, sexual names, comments and demands, following, flashing, public masturbation, groping, sexual assault, and rape" (p. 553). These forms of harassing behavior can be intimidating and intrusive for adolescents (Goldstein, Malanchuk, Davis-Kean, \& Eccles, 2007).

One major assumption in this study stems from the Bioecological theory (Bronfenbrenner (2005) which views a child's growth to be influenced by a network of subsystems. Accordingly, the child perception of risk and threat can by his/her interactions with various environmental settings such as the school, the neighborhood and the community. Furthermore, relying on the 
vulnerability and the ecological perspective, this study develops an adolescent sexual harassment index (ASHI), which will examine other dimensions relevant to sexual harassment such as the interpersonal aspect, cultural and traditional factors, and societal and environmental characteristics.

\section{Literature Review}

Research on violence and sexual abuse of adolescents has been expanding across the world (Al-Kylani, 2014; Vera-Gray, 2016). New areas of research have opened, such as cyberbullying (National Women's Law Center, 2018). Although characteristics, effects, and imputes for sexual harassment are different from sexual abuse, still the topic of adolescents' sexual harassment suffers from fragmentation, inconsistency, and separation (Stanley, 2000). In the following sections, a number of specific findings on child sexual harassment are identified and introduced as the foundation for this study.

The Prevalence of Adolescence Sexual Harassment

Adolescents are exposed to the trauma of sexual harassment early in their lives (AlAjami, 2016). For example, a majority reports indicate that their first peer-to-peer sexual harassment experience occurred in middle school, and some report first incidents occurring as early as elementary school (Murnen \& Smolak, 2000). Lacasse, Purdy, \& Mendelson (2003) believe that approximately $75 \%$ to $80 \%$ of students experience direct sexual harassment. In a Midwestern U.S. middle school study (graders 5-8) recently indicated that 28\% of girls and 34\% of boys reported perpetrating sexual harassment in the past year (Espelage, Basile, \& Hamburgr, 2012).

The prevalence of both perpetration and victimization experiences of sexual harassment and peer violence were comparable for boys and girls (Mumford, Okamoto, Taylor, \& Stein, 
2013). Studies show that approximately $75 \%$ to $80 \%$ of harassed youth report that they experienced harassment “often” or “occasionally" (Lichty \& Cambell, 2012). Recent studies show of 1,000 women surveyed, $67 \%$ experienced harassment in the street; $26 \%$ at a mall, restaurant, or store, and $20 \%$ on public transportation (Kearl, 2014).

The Effect of Sexual Harassment on Adolescents

Early experiences with sexual harassment have also linked indirectly to increase shame about one's body in both boys and girls (Lindberg et al., 2007). Consistent evidence has identified different types of effects of sexual harassment on victimized adolescents. On the educational level, sexual harassment interferes with a student's ability to do her school work and increases the likelihood of experiencing emotional/psychological abuse and sexual abuse (Mumford et al., 2013). Victimized adolescents report talking less in class (Lichty \& Campbell, 2012); difficulty paying attention in school, dropping out of activities, or dropping classes as a result of harassment. Strauss (2012) indicated that sexual harassment can have negative effects on students' health and attitudes about school, leading to diminished educational performance and academic withdrawal (AAUW Educational Foundation, 2001). Negative psychological effects of sexual harassment vary from feeling upset, worthless, and helpless (Davidson et al., 2016), and feeling worthless and helpless against the harassment (AAUW Educational Foundation, 2001).

Being a victim of sexual harassment makes victims feel afraid, nervous, and hesitant about things that were once no problem. It changes victims' lives and cheats them out of happiness, fun, and peace of mind, which ultimately influences the adolescents' views about the social and educational environment (Ormerod, Collinsworth, \& Perr, 2008). On the social level, victims of sexual harassment tend to avoid social situations and relationships with friends as a protective measure from sexual harassment (Stanely, 2000). Consequently, girls may become 
alienated and lose self-confidence (Lichty \& Campbell, 2012), and "learn infectious apathy, helplessness, and hopelessness" (Strauss, 2012, p. 97).

Street Sexual Harassment in Egypt

The prevalence of violence against adolescents in Arab countries has been documented. "Around 46 percent of ever married females age 18-64 years have experienced some form of spousal violence with 43 percent reported having been subjected to emotional violence, 32 percent physical violence and 12 percent sexual violence" (United Nations Population Fund, (UNPF), 2015, p. 62). Accordingly, researchers indicate that violence and insult have become part of the social fabric and the new reality of the Egyptian society (Egyptian Center for Women's Rights, 2007; and Gad-Allah, 2016).

A common form of sexual harassment that seems to represent a widespread phenomenon in Egypt is street harassment (Ilahi, 2009). Addressing life in Egypt, in Cairo streets are considered as major points of convergence as they contain various forms of social life and human activities; however, women and girls experience hostility and sexual harassment there on a daily basis (Egyptian Center for Women's Rights, 2007; Ilahi, 2009). When not in school, some of those unemployed youths spend their time roaming the streets looking for any type of behavioral experimentation (Amin, 2006). This situation tends to put young girls at the risk of victimization for sexual harassment.

\section{Theoretical Framework}

This study relies on a number of theoretical perspective as an attempt to view the way an adolescent perceive sexual harassment as a threat to his/her identity and life. Initially, the bioecological theory (Bronfenbrenner, 2005) emphasizes the child's development to be influenced by various levels of ecological systems. On the chronosystem, the child develops life 
experience based on not only the events that took place in the environment but on the way the child interact with these events. Accordingly, where events evolved in the child immediate environment which represents a sexual harassment risk "exposure," he or she develops a specific cognitive and behavioral mechanisms to guide the child's reactions and adjustment to these events. However, it can be emphasized that on the exposure or the adjustment levels which occur between the child and his/her environment, these event are viewed as a source of stress. Furthermore, the vulnerability and the objectification perspective can also perceived as foundation for examining the dynamics of adolescents' sexual harassment. Based on the vulnerability perspective, girls may be on the weak side as reflected in conditions of weakness, tendency, passivity, incapacitation, incapability, and powerlessness (Gilson, 2015, 2016). Female adolescents are in the boundaries of susceptibility to victimization by some individuals for "harmful wrongs, exploitation, or threats to one's interests or autonomy" (Mackenize, Rogers, \& Dodds, 2014, p. 6). Feminists theorize vulnerability as a state of tension and ambiguities of experiences of gender, sexuality, and power in contemporary life (Alcoff, 2009).

Sexual objectification of a female may lead to viewing female's behavior and clothing as a justification for being a target, and eventually sets the blame on the victim (Loughnan, Pina, Vasquez, \& Puvia, 2013). Proponents of the sexual objectification perspective focused on how people perceive women in a sexualized way, although fewer explanations are presented on how sexual objectification influences the view of females in real life The implicit associations between females' body and other objects or concepts may influence the individual's thoughts and attitudes toward females (Rudman \& Mescher, 2012).

Conceptualization of Sexual Harassment 
Sexual harassment has been considered a commonplace concept, and it may be mistakenly viewed as normal behavior. For example, Larkin (1994) presented three reasons that could lead girls to normalize such abnormal behavior: "(1) the frequency of the behavior, 2) the way in which the behavior was interpreted by others, particularly the male harassers; and 3) the fact that the topic of SH was seldom, if ever, discussed at school” (p. 62). Felix and McMahon (2006) studied sexual harassment of young females and found multiple forms of peer-to-peer victimization, which suggests significant associations between $\mathrm{SH}$ and both internalizing and externalizing problems. Recently, researchers have also begun to examine prejudice-based harassment, which takes into account the motivation behind the bullying and interpersonal violence (Mumford, et al., 2013).

The conceptualization of sexual harassment was influenced to a certain degree by existing myths and misrepresentation. The Alliance Against Sexual Coercion (AASC) (1980) compiled a list of erroneous assumptions people make about sexual harassment. These myths perpetuate sexual harassment, contribute to the victim's feelings of guilt, and induce women to keep quiet about it. Although few people believe all these myths, there is sufficient misinformation about SH to warrant exposure of the facts that contradict the myths. Operationalization

The operationalization of sexual harassment evolved around (a) the unwanted sexual or gender- based behavior by a person who has power over another (Strauss, 2012), (b) the behavior is informal, and may be more subtle because the two individuals may be peers, and it must be sexual and/or gender-based and severe, persistent, pervasive, and offensive enough to create a hostile educational environment, and (c) it interferes with the student's personal life and his or her ability to learn and engage in school activities. 
Existing measures for assessing sexual harassment started with the Sexual Experiences Questionnaire-High School version (SEQ-HS), which was used to measure direct SH experiences (Collinsworth, 2000). Items in the scale reflect a broad range of unwanted, sexual, or gender-focused inappropriate behaviors. It is important to acknowledge that the SEQ-SH also incorporates more items and accounts for more-specific forms of harassment, thus providing greater insight into the nuances of students' SH experience. The 29-item, modified SEQ-HS asked participants to report the frequency (i.e., " 0 " meaning never to " $2+$ " meaning twice or more) at which they experienced a variety of sexual harassment behaviors during the current school year (Ormerod et al., 2008).

The American Association of University Women's 1993 measure is a 13-item scale and is the most frequently adopted SH scale; however, limited psychometric or scale development information has been published on that measure or any of its reincarnations in other studies. In his attempt to measure sexual harassment among children, Mumford and colleagues (2013) summed affirmative responses from a 9-item scale to create separate overall prevalence estimate of sexual harassment victimization and harassment. The focus is to measure peer violence, both in terms of victimization and to determine the effect of physical and sexual violence on children (Mumford et al., 2013).

\section{Method}

This study develops an adolescents' sexual harassment index (ASHI) for Arab society, which fits with the existing cultural, social, and economic conditions in these societies. A theoretical model was defined to capture elements in the literature based on sexual harassment in Arab and non-Arab literature and available theoretical models. A number of variables that are commonly discussed in the literature are included (Al-Motalak, 2017; Al-Taiar, 2015; Fahd, 
2015; Gad-Allah, 2016). Other new variables, which represents factors and causes for the spread of sexual harassment in Arab countries and in Egypt were included in the model. These new concepts are believed to influence women's vulnerability to sexual harassment, such as social activities, the media, social stability, and religiosity.

Threats and vulnerability to sexual harassment. This construct refers to females' feeling of fear, worry, and concern of being targeted to be a victim of harassment. Twelve items were drawn to reflect how a female feels sense of vulnerability to harassment, the lack of safety measures for protection, and lack of laws and implementation of rules in the society to deter violators or to protect females' rights. Additionally, items were included to determine females' thoughts about reporting violations and the effect of reporting on their own safety, and how punishment of violators can be an effective solution to diminish harassment behaviors. Items in this domain were adopted from Estrada, Olson, Harbke, and Berggren (2011); Fitzgerald, Magley, Drasgow, and Waldo (1999) instruments on women's perception of harassment. The Cronbach's alpha for the 12 items on this subscale was .844 .

Exposure to sexual harassment. This domain is measured using 10 items, which identify the level of harassment behavior that a female may experience in her daily life. The items were adopted from the Sexual Experiences Questionnaire (Fitzgerald et al., 1999), the Turchik and Wilson (2008) survey, and the work of Wasti et al. (2000). The items include types of verbal and nonverbal remarks a woman may hear or suggestive stories or sexual discussion revealed with others in her presence. Nonverbal remarks include leering at the victim's body, offensive pinups, demands for sexual favors, unnecessary touching/unwanted contact, physical assault, and sexual coercion. The Cronbach's alpha for the 10 items on this subscale was .931 . 
Sense of pressure. This domain was measured by 10 items that are based on the Perceived Stress Scale (Cohen, Kamarck, \& Mermelstein, 1983). The items identify behavioral and personal reaction to life events, which may cause the female to feel upset, a loss of control, feeling irritated, coping with pressures, and ability to handle personal problems. The Cronbach's alpha for the 10 items on this subscale was .823 .

Social engagement and activity. A composite scale of 6 items to determine the level of participation of a female in social, sports, and cultural activities was used. These activities include being open to interact with people and share ideas though open meetings, volunteering in community initiatives, and participating in discussion with various groups. The Cronbach's alpha for the 6 items on this scale was .844 .

Media impact. Using the argument developed by Gerbner (1998) on the cultural effects of media on the people's lives, an 8-item scale was developed to assess the negative effect of media on the behavior of sexual harassment perpetrators. Specifically, the items measure females' perception of violent messages portrayed in the media; the stimulation of sex and the hidden meaning behind the media content; presentation of crime without discussion of punishment; and media views of women's abilities. The Cronbach's alpha for the 8 items on this subscale was .830 .

Society awareness. This construct refers to the level of understanding of sexual harassment from social, cultural, and legal dimensions. The construct is based on the assumption that societal realization of the risk and the effect of sexual harassment on the victims and the moral standards of the community are influenced by the political and economic stability of the environment people live in. Accordingly, 12 items were developed based on the societal stability protocol (Cline Center for Democracy, 2011) to assess females' views on their awareness of 
social, political, and economic conditions that may contribute to the practice of sexual harassment in the society. Items focused on sense of stability, law-breaking behaviors, inconsistency in punishment, sense of security, protection of citizens, and the general level of frustration. The Cronbach's alpha for the 12 items on this subscale was .880 .

Religiosity. This domain assesses how the level of religion influences the female's attitudes and opinion regarding her view of people's behavior, interaction, and conduct. A 9item scale was developed based on the work of Abu-Raiya (2008) on the assessment of religiosity of people. The item identifies the effect of religion on people's behavior, awareness of the influence of religion on people's thoughts, making life decisions based on religious instructions, the concept of rewards and punishment in religion, and how religion influences a person's judgment. The Cronbach's alpha for the 9 items on this subscale was .881 . Items on all subscales were measured on a response scale ranging from 1 to 7. Population and Sampling

The population of the study consisted of adolescent girls who reside in five governorates. A convenience sampling technique was used, yielding a total of 874 females age 17-18 years old ( $M=17.89$ years, $S D=0.32$ years $)$. The sample was distributed among these five governorates as Cairo (20\%), Al-Sharqiah (50\%), Al-Qaliubia ((5\%), Al-Daqahlia (5\%), and Al-Fayoum (5\%). adolescents were voluntarily asked to fill out the study survey and verbal consent was obtained. Participants learned about the confidentiality of the study and no names were obtained. The participants represent a diverse segment of adolescents in Egypt as they were school students, freshman in universities, and working groups from shops and small companies. Data Analysis 
Descriptive analysis of the 874 subjects who participated in the study reveals important characteristics. Most of the adolescents were 18 years old $(774,88.6 \%)$, and the remainder were 17 years old $(100,11.4 \%)$. In terms of marital status, most participants in the study were single $(622,71.2 \%)$, others were engaged $(215,24.6 \%)$ or married $(34,3.9 \%)$. Participants' education was distributed as $6(.07 \%)$ had elementary education, $705(80.7 \%)$ were high school students, and $155(17.7 \%)$ were college students. A majority of the participants, 508 (58.1\%), lived in villages, $192(22.0 \%)$ lived in small towns, and 174 (19.9\%) lived in large cities. A large portion of participants, 847 (96.9\%), were "unemployed" as full-time students, 20 (2.3\%) worked part time, and only $7(0.8 \%)$ held full-time positions. As for participants' type of dress, 14 (1.6\%) wore a niqab, $811(92.8 \%)$ wore a hijab, and only $36(4.1 \%)$ did not wear any covering over their heads.

\section{Results and Findings}

Because the factor structure of this instrument has not been fully investigated to date with this population, exploratory factor analysis was employed to examine the pattern of correlations in the data without imposing an a priori theory.

SPSS, version 25 (IBM, 2017), software was used to conduct exploratory factor analysis on the sample. Parallel analysis (Horn, 1965) suggested extracting 10 factors. Velicer's minimum average partial (Velicer, 1976) suggested extracting 9 factors. A scree plot suggested extracting four factors, although a less substantial pivot was apparent at the10th eigenvalue, accounting for the parallel analysis and minimum average partial solutions. Thus, both 4- and 10factor solutions were examined for their value in theory building. Principal axis factoring was used because it was desired to factor only the common variance among the study variables. The 
solution was submitted to oblimin rotation because there was no reason to believe that the constructs would be uncorrelated with one another.

Both the 4-factor solution and the 10-factor solution produced useful results. The 4-factor solution was favored because it had simpler structure due to having fewer items with crossloadings than the 10-factor solution. It was desired to reduce the number of items from the 4factor rotated solution. Items were retained if they had a structure coefficient with magnitude .50 or greater on at least one of the four factors. The .50 threshold is more stringent than values of .40 or .30 typically applied in the literature. The more stringent threshold was chosen to select very strong items for theory building. This resulted in 18 items eliminated from further analysis.

The remaining 49 items were subjected to reanalysis using principal axis factoring with oblimin rotation as before. The 4-factor solution alone was examined. With oblimin rotation, two types of loadings were produced. Structure coefficients represent the correlation between the factor and the item. Pattern coefficients represent the unique relationship between a factor and an item, controlling for the other factors. The communalities and structure and pattern coefficients for the 4-factor rotated solution are found in Table 1. Given that commonalities in this study ranged from .18 to .68 , and 10 to 17 items were associated with individual factors, the sample size in this study was appropriate (Hogarty, Hines, Kromrey, Ferron, \& Mumford, 2005; MacCallum, Widaman, Preacher, \& Hong, 2001; MacCallum, Widaman, Zhang, \& Hong, 1999). Based on the study plan, items included in the analysis had thresholds falling just below the .5 criterion. Finally, the analysis concluded with four factors: Factor 1 "society awareness and media impacts"; Factor 2 "interpersonal characteristics and exposure to sexual harassment"; Factor 3 "personal activities and religiosity," and "Factor 4 sense of self and reality." 
The four factors accounted for $42.38 \%$ of the variability in the study variables. The factor correlation matrix is in Table 4 along with maximal reliability for each factor. The maximal reliabilities for all four factors were high, indicating good reliability (Hancock \& Mueller, 2001; Raykov, 2004).

$<$ Table 2 here>

Discussion

This study examined the factor structure of an index that addresses the interpersonal, social, and cultural aspects of the children's perception of threat and vulnerability to sexual harassment. The bioecological theory emphasizes the adolescents' perspective on viewing sexual harassment as an environmental threat. Based on such view, an adolescents' sense of threat and other serious problems can be the product of daily interactions among material and value subsystems. In a sense this ASHI provides empirical justification for the ecological system perspective which enhances the contribution of such perspectives on explaining human interactions with complex social phenomenon.

The construct of vulnerability represents the basis for the child's fear, apprehension, and worry of being exposed or targeted for any emotional and physical harm or pain (Mackenzie et al., 2014). In this view, vulnerability as a construct is determined by specific feelings or behavior that set the child mentally and emotionally in a condition of passivity and incapability (Gilson, 2015). This construct was reflected in Factor 3 of the ASHI, "interpersonal, activities and religion." The condition of threat can contribute to the vulnerability construct as the society may endure specific characteristics, culture, and values that implicitly tolerate or ignore sexual harassment against children. Accordingly, in the ASHI Factor 1, "society and media" validated the climate and social conditions that manifest sexual harassment behavior. Furthermore, 
children's experience of threat of sexual harassment was to some extent influenced by assumptions drawn from the objectification perspective in which females are portrayed by the media and other forms of public communication as sex objects (Loughnan et al., 2013).

As the focus of the adolescents' sexual harassment instrument was on the harassment behavior (Fitzgerald et al., 1997), or the experience and types of harassment (Collinsworth, 2000), the ASHI added other critical factors to the literature. For example, the ASHI recognizes the child's sense of self and the world around him or her, leading to the victimization state. Accordingly, Factor 4, "sense of interpersonal equality" provided the linkage between the adolescent's view of self in relation to the risks and threats around him or her. The ASHI introduces new perspectives to the way the research can consider and view the complexity of adolescents' sexual harassment. For researchers who show interest in examining sexual harassment as a negative social phenomenon, it is critical to address the cultural aspects and the nature of interrelations among social, economic and political systems existed in the community. Accordingly, negative interactions produce risky dynamics leading to the growth of unhealthy environment which may cause tremendous impact on adolescents' growth and adjustment. Practitioners who work on providing adolescents with guidance and mental health services may benefit from the ASHI to assess the adolescent's sense of safety, trust on own ability, views of exposure to sexual harassment and his/her perspective on existing system within the environment which can help deter harassment behavior and promote awareness and sense of self among adolescents. Finally, as with all exploratory analyses, it is important to remember that the model presented is only one possible representation of the relations among the variables. Alternative models may explain the data just as well or better than the model found in this study. 
Policy makers, therapists, educators and law enforcements can learn from this study the ways adolescents perceive the risk and threats of sexual harassment, as it became part of their social experience. Before setting policies to eliminate the risk of sexual harassment on adolescents or raising the awareness of such phenomenon, it is imperative for many people to assess adolescents' views, feelings and thoughts about what generates such a problem and how female adolescents perceive it within the context of social, ecological and cultural parameters. Furthermore, therapists and social workers may benefit from the ASHI to assess the level of threats that adolescents experience and how such SH threat impact other functions in their life.

\section{Limitations}

These results are exploratory and represent the structure of the data for this particular sample. The model suggested by the results of this study should be cross-validated with a new sample to assess the stability of the factor structure. 


\section{References}

AAUW Educational Foundation. (2001). Hostile hallways: Bullying, teasing, and sexual harassment in schools. Washington, DC: Author.

Abu-Raiya, H. (2008). A psychological measure of Islamic religiousness: Evidence for relevance, reliability, and validity. Dissertation submitted to the Graduate College of Bowling Green State University.

Al-Ajami, R. M. (2016). The role of the family and society in facing sexual harassment phenomenon towards children. Education Science, Kuwait- Egypt.

Alliance Against Sexual Coercion. (1980). University grievance procedures, Title IX, and sexual harassment on campus. Boston, MA: Author.

Alcoff, L. M. (2009). Discourses of sexual violence in a global framework. Philosophical Topics, 37(2), 123-139.

Al-Kylani, R. M. (2014). Sexual harassment of women and the disruption of the value system in the Egyptian society. Arab Journal of Sociological Science, 1, 13- 33.

Al-Motalka, F. I. (2017). Sexual harassment against Jordanian women and its relation with some variables: The view of Jordon University students. Studies in Humanity and Social Sciences Journal, 44(2), 24-36.

Al-Taiar, F. A. (2015). Sexual harassment in UAE middle schools: A student counselor's perspective. Police Thoughts Journal, Al-Sharja Police Academy, 24(40), 55-76.

Bronfenbrenner, U. (2005). Making human beings human, bioecological prespectives on human development. Thousand Oaks: California.

Amin, G. (2006). Socio-economic interpretations of the west el Balad events. Presented at the IGWS sexual harassment Forum, December 4, 2006, Cairo.

Appollis, M., Lund, C., De Varies, P. J., \& Mathews, C. (2015). Adolescents' and adults' experiences of being surveyed about violence and abuse: A systematic review of harms, benefits, and regrets. American Journal of Public Health, 105(2), 31-45.

Doi:10,2105/AJPH.2014.302293

Cline Center for Democracy. (2011). Gauging civil unrest with speed data: The societal stability and the intensity of civil unrest. University of Illinois at Urbana-Champaign.

Cohen, S., Kamarck, T., \& Mermelstein, R. (1983). A global measure of perceived stress. Journal of Health and Social Behavior, 24(4), 385-396.

Collinsworth, L. L. (2000). Sexual harassment in high school. (Unpublished master's thesis.) University of Illinois at Urbana-Champaign.

Davidson, M. M., Butchko, M. S., Robbins, K., Sherd, L, W., \& Gervais, S. J. (2016). The mediating role of perceived safety on street harassment and anxiety. Psychology of Violence, $6(4), 553-561$. 
Egyptian Center for Women's Rights. (2007). Campaign against sexual harassment. Retrieved from http://www.ahewar.org/eng/show.art.asp?aid=292

Espelage, D. L., Basile, K. C., Humburger, M. E. (2012). Bullying preparation and subsequent sexual violence perpetration among middle school students. Journal of Adolescent Health, 50(1), 60-65.

Estrada, A. X., Olson, K. J., Harbke, C. R., \& Berggren, A. W. (2011). Evaluating a brief scale measuring psychological climate for sexual harassment. Military Psychology, 23, 410-432. DOI:10:1080/08995.2011.589353.

Fagerlund, M., \& Ellonen, N. (2016). Children's experiences of completing a computer-based violence survey: Finnish child victim survey revisited. Journal of Child Sexual Abuse, 2(5), $556-576$.

Fahd, A. A. (2015). Sexual harassment in middle schools: Students' perceptions in UAE. AlSharja Police Academy Journal, 24 (94), 11-27.

Felix, E. D., \& McMahon, S. D. (2006). Gender and multiple forms of peer victimization: How do they influence adolescent psychological adjustment? Violence and Victims, 21, 707-724.

Fitzgerald, L. F., Magley, V. J., Drasgow, F., \& Waldo, C. R. (1999). Measuring sexual harassment in the military: The Sexual Experiences Questionnaire (SEQ-DoD). Military Psychology, 11(3), 243-63.

Fitzgerald, L. F., Swan, S., \& Magley, V. J. (1997). But was it really sexual harassment? Legal, behavioral, and psychological definitions of the workplace victimization of women, In W. O'Donohue (Ed.), Sexual harassment theory, research, and treatment (pp. 5-28). Needham Heights, MA: Allyn \& Bacon.

Gad-Allah, A. A. (2016). A suggested program from a generalist social work perspective to educate middle school students about the impact of sexual harassment - Egypt. Egyptian Social Workers Association Journal, 55, 24-42.

Gerbner, G. (1998). Cultivation analysis: An overview. Mass Communication and Society, 1(3/4), 175-194. DOI: 10.1080/15205436.1998.9677855.

Gilson, E. C. (2015). Intersubjective vulnerability, ignorance, and sexual violence. In M. Gross \& L. McGoey (Eds.), Routledge international handbook of ignorance studies (pp. 228-238). Abington-on-Thames, England: Routledge

Gilson, E. C. (2016). Vulnerability and victimization: Rethinking key concepts in feminist discourses on sexual violence. Journal of Women in Culture and Society, 40(1), 71-98.

Gloppen, K. M., Gower, A. M., McMorris, B. J., \& Eisenberg, M. E. (2017). Association between peer harassment and school risk and protection profiles. Journal of School Health, 87(11), 832-841.

Goldstein, S. E., Malanchuk, O., Davis-Kean, P. E., \& Eccles, J. S. (2007). Risk factors of sexual harassment by peers: A longitudinal investigation of African American and European American adolescents. Journal of Research on Adolescence, 17, 285-300. 
Hancock, G. R., \& Mueller, R. O. (2001). Rethinking construct reliability within latent variable systems. In R. Cudeck, S. Du Toit, \& D. Sörbom (Eds.), Structural equation modeling: Present and future (pp. 195-216). Lincolnwood, IL: Scientific Software International.

Hill, C., \& Kearl, H. (2011). Crossing the line: Sexual harassment in schools. Washington, DC: AAUW.

Hogarty, K. Y., Hines, C. V., Kromrey, J. D., Ferron, J. M., \& Mumford, K. R. (2005). The quality of factor solutions in exploratory factor analysis: The influence of sample size, communality, and overdetermination. Educational and Psychological Measurement, 65, 202-226.

Horn, J. L. (1965). A rationale and test for the number of factors in factor analysis.

Psychometrika, 30, 179-185.

IBM Corp. (2017). IBM SPSS Statistics for Windows, Version 25.0. Armonk, NY: IBM Corp.

Ilahi, O. O. (2009). Gendered contestations: An analysis of street harassment in Cairo and its implications for women's access to public spaces. Retrieved from http://www.aucegypt.edu/gapp/igws/graduate/documents/surfacing-vol2n_05ilahi.pdf

Kearl, H. (2014). Unsafe and harassed in public spaces: A national street harassment report. Stop Street Harassment. Retrieved from http://www.stopstreetharassment.org/wpcomment/uploads/2012/2014- National-SSH-Street-Harrasment-Report.pdf

Lacasse, A., Purdy, K. T., \& Mendelson, M. J. (2003). The mixed company they keep: Potentially offensive sexual behaviors among adolescents. International of Behavioral Development, 27, 532-540.

Larkin, J. (1994). Sexual harassment: High school girls speak out. Toronto, Ontario, Canada: Second Story Press.

Lichty, L. F., \& Campbell, R. (2012). Targets and witnesses: Middle school students' sexual harassment experiences. Journal of Early Adolescence, 32(3), 414-430.

Lindberg, S. M., Grabe, S., \& Hyde, J. S. (2007). Gender, pubertal development, and peer sexual harassment predict objectified body consciousness in early adolescence. Journal of Research on Adolescence, 17(4), 723-742.

Loughnan, S., Pina, A., Vasquez, E. A., \& Puvia, E., (2013). Sexual objectification increases rape victim blame and decreases perceived suffering. Psychology of Women Quarterly, 37, 455-461. Retrieved from http://dx.doi.org/10.1177/036168431485718

MacCallum, R. C., Widaman, K. F., Preacher, K. J., \& Hong, S. (2001). Sample size in factor analysis: The role of model error. Multivariate Behavioral Research, 36, 611-637.

MacCallum, R. C., Widaman, K. F., Zhang, S., \& Hong, S. (1999). Sample size in factor analysis. Psychological Methods, 4, 84-99. 
McClinton, A. T., Lund, C., De Vries, P. J. \& Mathews, C. (2015). Adolescents' and adults' experiences as being surveyed about violence and abuse: A systemic review of harms, benefits, and regrets. American Journal of Public Health, 105(2), 31-45.

McCurm, A. S. (2017). I am not a prostitute: How young black women challenge street-based micro-interactional assaults. Sociological Focus, 50(10), 52-65.

Mackenzie, C., Rogers, W., \& Dodds, S. (2014). Vulnerability: New essays in ethics and feminist philosophy. New York, NY: Oxford University Press.

Mumford, E. A., Okamoto, J., Taylor, B. G., \& Stein, N. (2013). Middle school sexual harassment, violence and social networks. American Journal of Health Behavior, 37(6), 769-779.

Murnen, S. K., \& Smolak, L. (2000). The experience of sexual harassment among grade-school students: Early socialization of female subordination? Sex Roles, 43(1/2), 1-17.

National Women's Law Center. (2018). Cyberbullying and sexual harassment: FactsheetCyberbullying and Title IX. Washington, DC. Retrieved from http://nwlc.orgsuites/default/files/cyberbullingfactsheet.pdf

Ormerod, A. J., Collinsworth, L. L., \& Perry, L. A. (2008). Critical climate: Relations among sexual harassment, climate, outcomes for high school girls and boys. Psychology of Women Quarterly, 32, 113-125.

Raykov, T. (2004). Estimation of maximal reliability: A note on a covariance structure modelling approach. British Journal of Mathematical and Statistical Psychology, 57(1), 21-27.

Rudman, L. A., \& Mescher, K. (2012). Of animals and objects: Men's implicit dehumanization of women and likelihood of sexual aggression. Personality and Social Psychology Bulletin, 38, 734-746. Retrieved from http:dx.doi.org/10.1177/0146167212436401

Stanley, D, (2000). Student-on-student sexual harassment. New York, NY: The Rosen Publishing Group.

Strauss, S. L. (2012). Sexual harassment and bullying: A guide to keeping kids safe and holding schools accountable. New York, NY: Rowan \& Littlefield.

Turchik, J. A., \& Wilson, S. M. (2008). Sexual assault in the U.S. military: A review of the literature and recommendations for the future. Aggression and Violent Behavior, 15(4), $267-277$.

United Nation Population Fund (UNPF). (2015). The Egypt Economic Cost of Gender-Based Violence Survey. Cairo, Egypt: The Central Agency for Public Mobilization and Statistics (CAPMAS).

Velicer, W. F. (1976). Determining the number of components from the matrix of partial correlations. Psychometrika, 41, 321-327. 
Vera-Gray, F. (2016). Men's stranger intrusions: Rethinking street harassment. Women's Studies International Forum, 58, 9-17. Retrieved from http://dx.doi.org/10.1016/j.wsif.2016.04,001

Wasti, S. A., Bergman, M. E., Glomb, T. M., \& Drasgow, T. (2000). Test of the cross-cultural generalizability of a model of sexual harassment. Journal of Applied Psychology, 85(5), 766778. 